\title{
Determination of Metal Contents of Various Fibers Used in Textile Industry by MP-AES
}

\author{
Şana Sungur and Fatih Gülmez \\ Department of Chemistry, Science and Letters Faculty, Mustafa Kemal University, 31024 Hatay, Turkey \\ Correspondence should be addressed to Şana Sungur; sanasungur@hotmail.com
}

Received 28 July 2015; Revised 14 September 2015; Accepted 14 September 2015

Academic Editor: Maria Carmen Yebra-Biurrun

Copyright (C) 2015 Ş. Sungur and F. Gülmez. This is an open access article distributed under the Creative Commons Attribution License, which permits unrestricted use, distribution, and reproduction in any medium, provided the original work is properly cited.

\begin{abstract}
The concentrations of metals ( $\mathrm{Al}, \mathrm{Cd}, \mathrm{Co}, \mathrm{Cr}, \mathrm{Cu}, \mathrm{Fe}, \mathrm{Mn}, \mathrm{Ni}, \mathrm{Pb}, \mathrm{Tl}$, and $\mathrm{Zn}$ ) in various textile fibers (cotton, acrylic, polyester, nylon, viscose, and polypropylene) of different colors (red, white, green, blue, yellow, orange, black, brown, purple, pink, navy, burgundy, beige, and grey) were determined by microwave plasma-atomic emission spectroscopy (MP-AES). Textile fibers were collected from the various textile plants in Gaziantep-Kahramanmaraş, Turkey. Heavy metals concentrations in all examined textile fibers after wet digestion were found to be high, whereas in the artificial sweat extract they were low. The only lead concentrations in textile fibers analyzed after extraction in the artificial sweat solution were found higher than limit values given by Oeko-Tex.
\end{abstract}

\section{Introduction}

The textile industry has been condemned as being one of the world's offenders in terms of pollution because it requires a great amount of chemicals [1]. 2000 different chemicals are used in the textile industry from dyes to transfer agents.

Residues of antimony, copper, and chromium in dyestuffs are possible from the use of catalysts in the synthesis of some dye intermediates. Some reactive dyes contain metal complexes such as that of copper, nickel, cobalt, and chromium. It is also possible for dyestuffs with metal-free chromophores to contain metallic impurities, originating from the raw materials used in manufacture.

Traditionally produced fabrics contain residuals of chemicals used during their manufacture, chemicals that evaporate into the air we breathe or are absorbed through our skin. Some of the chemicals are carcinogenic or may cause harm to children even before birth, while others may trigger allergenic reactions in some people. Prolonged exposure to heavy metals may cause health problems such as kidney failure, emphysema, allergies, and even cancer. For this reason, the determination of the metal content of textile materials is very important.

Oeko-Tex Standard 100 is an international testing and certification system for textiles, limiting the use of certain chemicals. Textiles with this label are proven to remain below the set limit values for certain harmful substances. Oeko-Tex Standard 100 limit values were given in Table 1.

Several analytical techniques, such as anodic stripping voltammetry [2], spectrophotometry [3], atomic absorption spectrometry $[4,5]$, inductively coupled plasma optical emission spectrometry [6-9], inductively coupled plasmamass spectrometry [10], and X-ray fluorescence spectrometry [11] are used commonly for the determination of total or extractable amounts of heavy metals in textile. However, microwave plasma-atomic emission spectroscopy (MP-AES) represents a completely new elemental analytical technique that has been designed to improve analytical performance and productivity, while decreasing operating costs by eliminating the flammable and/or expensive gas requirements used in typical elemental analytical techniques.

In this study, the concentrations of metals $(\mathrm{Al}, \mathrm{Cd}, \mathrm{Co}$, $\mathrm{Cr}, \mathrm{Cu}, \mathrm{Fe}, \mathrm{Mn}, \mathrm{Ni}, \mathrm{Pb}, \mathrm{Tl}$, and $\mathrm{Zn}$ ) in various textile fibers (cotton, acrylic, polyester, nylon, viscose, and polypropylene) of different colors (red, white, green, blue, yellow, orange, black, brown, purple, pink, navy, burgundy, beige, and grey) were determined by MP-AES. Extraction with artificial sweat solution and wet digestion were performed before MP-AES analysis. Both comparisons of two digestion methods were carried out. 
TABLE 1: Oeko-Tex Standard 100 limit values $\left(\mathrm{mg} \mathrm{kg}^{-1}\right)$.

\begin{tabular}{|c|c|c|c|c|}
\hline Heavy metals & Baby wear & With skin contact & Without skin contact & Accessories \\
\hline Antimony (Sb) & 30.0 & 30.0 & 30.0 & - \\
\hline Arsenic (As) & 0.2 & 1.0 & 1.0 & 1.0 \\
\hline Lead $(\mathrm{Pb})$ & 0.2 & 1.0 & 1.0 & 1.0 \\
\hline Cadmium (Cd) & 0.1 & 0.1 & 0.1 & 0.1 \\
\hline Chromium (Cr) & 1.0 & 2.0 & 2.0 & 2.0 \\
\hline Cobalt (Co) & 1.0 & 4.0 & 4.0 & 4.0 \\
\hline Copper $(\mathrm{Cu})$ & 25.0 & 50.0 & 50.0 & 50.0 \\
\hline Nickel (Ni) & 1.0 & 4.0 & 4.0 & 4.0 \\
\hline Mercury (Hg) & 0.02 & 0.02 & 0.02 & 0.02 \\
\hline
\end{tabular}

\section{Experimental}

2.1. Reagents and Standards. Multielement standard solution IV was used for checking the accuracy of the measurements by MP-AES. All chemicals were obtained from Merck (Darmstadt, Germany). All chemicals used were of analytical reagent grade and were at least $99.5 \%$ pure.

2.2. Collection of Textile Fibers. Six types of textile fibers (cotton, acrylic, polyester, nylon, viscose, and polypropylene) of different colors (red, white, green, blue, yellow, orange, black, brown, purple, pink, navy, burgundy, beige, and grey) were collected from the various textile plants in GaziantepKahramanmaraş, Turkey.

\subsection{Sample Preparation}

2.3.1. Extraction in the Artificial Sweat Solution. Textile fibers were dried for $48 \mathrm{~h}$ at $60^{\circ} \mathrm{C}$ before analysis and afterwards cut and weighed. The artificial sweat solution was prepared as described in the ISO 3160/2 standard by dissolving $20 \mathrm{~g}$ $\mathrm{NaCl}, 17.5 \mathrm{~g} \mathrm{NH}_{4} \mathrm{Cl}, 5 \mathrm{~g} \mathrm{CH}_{3} \mathrm{COOH}$, and $15 \mathrm{~g}$ lactic acid in $1 \mathrm{~L}$ of deionized water. The $\mathrm{pH}$ was adjusted to 4.7 by adding the respective amount of $0.1 \mathrm{~N} \mathrm{NaOH}$. $0.5 \mathrm{~g}$ of a sample was mixed for $24 \mathrm{~h}$ with $40 \mathrm{~mL}$ of artificial sweat solution. After filtration, the solutions were analyzed by MP-AES.

2.3.2. Wet Digestion Procedure. Textile fibers were dried for $48 \mathrm{~h}$ at $60^{\circ} \mathrm{C}$, cut, and weighed. One gram of a sample was heated at $110^{\circ} \mathrm{C}$ for $55 \mathrm{~min}$ with $10 \mathrm{~mL}$ of $1: 5 \mathrm{H}_{2} \mathrm{O}_{2}$ $(30 \%) / \mathrm{HNO}_{3}(70 \%)$ acid mixture. The resulting solutions were cooled and filtered. After filtration, the solutions were filled up to $25 \mathrm{~mL}$ with deionized water. Then, the solutions were analyzed by MP-AES.

2.4. MP-AES Analysis. MP-AES analysis was performed on an Agilent 4100 instrument. The Agilent MP Expert software was used to automatically substract the background signal from the analytical signal. A background spectrum from a blank solution was recorded and automatically substracted from each standard and sample solution analyzed. The software was also used to optimize the nebulization pressure and the viewing position for each wavelength selected to maximize sensitivity. The MP-AES conditions were the following:
TABLE 2: The values of correlation coefficients, LOD, and LOQ of examined heavy metals.

\begin{tabular}{lccc}
\hline $\begin{array}{l}\text { Heavy } \\
\text { metals }\end{array}$ & $\begin{array}{c}\text { Correlation } \\
\text { coefficient }\left(R^{2}\right)\end{array}$ & $\begin{array}{c}\text { LOD } \\
\left(\mathrm{mg} \mathrm{L}^{-1}\right)\end{array}$ & $\begin{array}{c}\text { LOQ } \\
\left(\mathrm{mg} \mathrm{L}^{-1}\right)\end{array}$ \\
\hline $\mathrm{Fe}$ & 0.999 & 0.343 & 1.142 \\
$\mathrm{Zn}$ & 0.996 & 0.705 & 2.348 \\
$\mathrm{Cd}$ & 0.997 & 0.415 & 1.382 \\
$\mathrm{Cu}$ & 0.999 & 0.256 & 0.852 \\
$\mathrm{Co}$ & 0.999 & 0.202 & 0.673 \\
$\mathrm{Ni}$ & 0.999 & 0.118 & 0.393 \\
$\mathrm{Al}$ & 0.999 & 0.123 & 0.409 \\
$\mathrm{Mn}$ & 0.999 & 0.059 & 0.196 \\
$\mathrm{~Pb}$ & 0.999 & 0.088 & 0.293 \\
$\mathrm{Cr}$ & 0.999 & 0.101 & 0.336 \\
$\mathrm{Tl}$ & 0.998 & 0.285 & 0.949 \\
\hline
\end{tabular}

(i) Nebulizer: OneNeb;

(ii) spray chamber: double pass glass cyclonic;

(iii) read time: $5 \mathrm{~s}$;

(iv) stabilization time: $15 \mathrm{~s}$;

(v) number of replicates: 3;

(vi) optical system: Czerny-Turner design monochromator with $600 \mathrm{~mm}$ focal length and fixed entrance slit;

(vii) detector: back-thinned solid state CCD detector $(532 \times 128$ pixels $)$;

(viii) analytes (wavelengths): Al $396.15 \mathrm{~nm}$; Cr $425.43 \mathrm{~nm}$; $\mathrm{Cu} 324.75 \mathrm{~nm}$; Fe $259.94 \mathrm{~nm}$; Mn $403.08 \mathrm{~nm}$; $\mathrm{Ni} 352.45 \mathrm{~nm}$; $\mathrm{Pb} 405.78 \mathrm{~nm}$; Zn $213.86 \mathrm{~nm}$; Co $340.51 \mathrm{~nm}$; Cd $228.80 \mathrm{~nm}$; and Tl $535.05 \mathrm{~nm}$.

2.5. Quality Control. The calibration standards were prepared in the range of $1-5 \mathrm{mg} \mathrm{L}^{-1}$ using a multielement standard solution in a matrix of $5 \% \mathrm{HNO}_{3}$. In all cases, the correlation coefficients of linear function were better than 0.995. Limits of detection (LOD) and limit of quantification (LOQ) were calculated from three and ten times the standard deviations for 15 consecutive blank measurements divided by the calibration curve slope, respectively. The values obtained for all metals are listed in Table 2. 


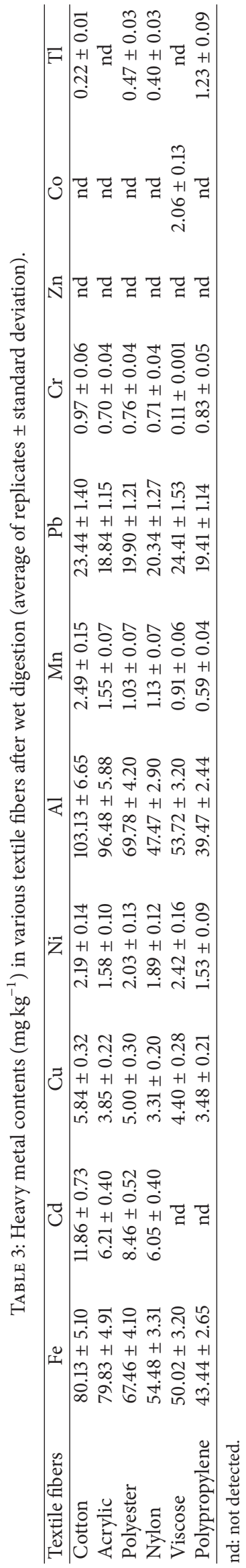


TABLE 4: Heavy metal contents $\left(\mathrm{mg} \mathrm{kg}^{-1}\right)$ in various textile fibers after extraction in the artificial sweat solution (average of replicates \pm standard deviation).

\begin{tabular}{lccccc}
\hline Textile fibers & $\mathrm{Cu}$ & $\mathrm{Al}$ & $\mathrm{Mn}$ & $\mathrm{Pb}$ & $\mathrm{Cr}$ \\
\hline Cotton & $3.16 \pm 0.20$ & $5.52 \pm 0.30$ & $1.44 \pm 0.09$ & $1.57 \pm 0.10$ & $0.11 \pm 0.01$ \\
Acrylic & $2.35 \pm 0.14$ & $3.74 \pm 0.23$ & $0.35 \pm 0.02$ & $1.68 \pm 0.10$ & $0.25 \pm 0.02$ \\
Polyester & $2.04 \pm 0.13$ & $2.70 \pm 0.16$ & $0.39 \pm 0.02$ & $1.08 \pm 0.07$ & nd \\
Nylon & $2.01 \pm 0.12$ & $2.46 \pm 0.16$ & $0.62 \pm 0.04$ & $0.74 \pm 0.04$ & nd \\
Viscose & $2.11 \pm 0.13$ & $3.18 \pm 0.20$ & $0.39 \pm 0.02$ & $0.66 \pm 0.04$ & nd \\
Polypropylene & $2.94 \pm 0.19$ & $4.70 \pm 0.30$ & $0.37 \pm 0.02$ & $1.37 \pm 0.08$ & $0.37 \pm 0.02$ \\
\hline
\end{tabular}

nd: not detected.

TABLE 5: Literature values of heavy metals $\left(\mathrm{as} \mathrm{mg} \mathrm{kg}^{-1}\right)$ in textile fibers.

\begin{tabular}{|c|c|c|c|c|c|}
\hline Literature & Metals & Cotton & Polyester & Nylon & Viscose \\
\hline \multirow{5}{*}{ Saracoglu et al., 2003 [5] } & $\mathrm{Fe}$ & $0.44-4.49$ & $0.23-28.90$ & $3.42-29.90$ & $1.99-4.41$ \\
\hline & $\mathrm{Cu}$ & $0.26-0.78$ & nd- -0.36 & nd-0.48 & $0.26-11.20$ \\
\hline & $\mathrm{Ni}$ & $0.20-0.70$ & $0.29-3.63$ & $0.76-3.63$ & $0.30-1.68$ \\
\hline & $\mathrm{Pb}$ & $0.28-0.30$ & nd-0.76 & $0.31-3.76$ & $0.40-0.80$ \\
\hline & $\mathrm{Zn}$ & $0.40-5.00$ & $0.90-4.70$ & nd -0.90 & $2.40-3.00$ \\
\hline \multirow{6}{*}{ Doğan et al., 2002 [11] } & $\mathrm{Cu}$ & $0.28-0.84$ & $0.04-0.34$ & $0.04-0.32$ & $0.12-13.58$ \\
\hline & $\mathrm{Ni}$ & $0.24-1.52$ & $0.20-0.24$ & $0.24-0.26$ & $0.16-0.98$ \\
\hline & $\mathrm{Pb}$ & $0.18-6.00$ & $0.05-1.08$ & $1.08-2.50$ & $0.34-0.90$ \\
\hline & $\mathrm{Cr}$ & $0.44-1.12$ & nd- -0.42 & nd & $0.22-0.90$ \\
\hline & $\mathrm{Zn}$ & $0.42-2.16$ & $0.92-4.04$ & $0.14-0.92$ & $1.48-3.46$ \\
\hline & Co & $0.04-0.96$ & $0.08-0.16$ & $0.12-0.16$ & $0.01-0.06$ \\
\hline \multirow{5}{*}{ Tuzen et al., 2008 [4] } & $\mathrm{Fe}$ & $3.55-34.3$ & - & - & - \\
\hline & $\mathrm{Cu}$ & $0.76-341$ & - & - & - \\
\hline & $\mathrm{Ni}$ & $1.20-4.69$ & - & - & - \\
\hline & $\mathrm{Zn}$ & $0.63-4.84$ & - & - & - \\
\hline & $\mathrm{Mn}$ & $1.02-2.50$ & - & - & - \\
\hline \multirow{4}{*}{ Rezić and Steffan, 2007 [6] } & $\mathrm{Cu}$ & $0.05-0.21$ & 0.05 & - & $0.05-0.06$ \\
\hline & $\mathrm{Ni}$ & $0.05-0.10$ & 0.08 & - & $0.09-0.10$ \\
\hline & Mn & $0.03-0.05$ & $1.17-2.17$ & - & $0.31-0.36$ \\
\hline & $\mathrm{Al}$ & $0.11-0.17$ & $0.27-0.29$ & - & $0.21-0.29$ \\
\hline \multirow{5}{*}{ Present study } & $\mathrm{Cu}$ & $1.96-4.40$ & $1.93-2.16$ & $1.92-2.36$ & $2.03-2.26$ \\
\hline & $\mathrm{Pb}$ & $1.23-1.83$ & $0.75-1.52$ & $0.65-0.95$ & $0.55-0.76$ \\
\hline & $\mathrm{Cr}$ & nd-0.11 & nd & nd & nd \\
\hline & $\mathrm{Mn}$ & $0.49-2.30$ & $0.26-1.07$ & $0.26-1.04$ & $0.23-0.86$ \\
\hline & $\mathrm{Al}$ & $2.27-7.43$ & $1.07-3.85$ & $0.99-3.37$ & $2.06-9.65$ \\
\hline
\end{tabular}

nd: not detected; -: not examined.

\section{Results and Discussion}

Heavy metal contents in the examined various textile fibers (cotton, acrylic, polyester, nylon, viscose, and polypropylene) after wet digestion were presented in Table 3. Iron (43.44$80.13 \mathrm{mg} \mathrm{kg}^{-1}$ ) and aluminum (39.47-103.13 $\mathrm{mg} \mathrm{kg}^{-1}$ ) were detected in the highest concentrations in all examined textile fibers. Zinc was not found in any of the textile fibers. Cobalt was only found in viscose fibers as $2.06 \mathrm{mg} \mathrm{kg}^{-1}$. The concentrations of some heavy metals were determined considerably higher than the mean concentrations (manganese $\left(22.37 \mathrm{mg} \mathrm{kg}^{-1}\right)$ in green cotton fibers; chromium $\left(17.51 \mathrm{mg} \mathrm{kg}^{-1}\right)$ in black acrylic fibers; copper $\left(17.74 \mathrm{mg} \mathrm{kg}^{-1}\right)$ in green polyester fibers; cobalt $\left(9.18 \mathrm{mg} \mathrm{kg}^{-1}\right)$ in pink viscose fibers; and chromium ( $4.58 \mathrm{mg} \mathrm{kg}^{-1}$ ) in yellow polypropylene fibers). The levels of cadmium and lead in all examined textile fibers were found considerably higher than the values demanded by Oeko-Tex. The concentrations of other heavy metals $(\mathrm{Cu}, \mathrm{Ni}, \mathrm{Cr}$, and $\mathrm{Co})$ were determined to be within the normal limits. There is no any information about iron, manganese, aluminium, zinc, and thallium in limit values given by Oeko-Tex.

Heavy metal contents in the examined various textile fibers (cotton, acrylic, polyester, nylon, viscose, and polypropylene) after extraction in the artificial sweat solution were presented in Table 4. The concentrations 
of lead were found higher than the Oeko-Tex standards in cotton $\left(1.57 \mathrm{mg} \mathrm{kg}^{-1}\right)$, acrylic $\left(1.68 \mathrm{mg} \mathrm{kg}^{-1}\right)$, polyester $\left(1.08 \mathrm{mg} \mathrm{kg}^{-1}\right)$, and polypropylene $\left(1.37 \mathrm{mg} \mathrm{kg}^{-1}\right)$ fibers. Chromium (0.11-0.37 $\left.\mathrm{mg} \mathrm{kg}^{-1}\right)$ and copper (2.01$3.16 \mathrm{mg} \mathrm{kg}^{-1}$ ) levels in all examined textile fibers were determined to be within the normal limits. Iron, cadmium, nickel, zinc, cobalt, and thallium were not determined in any of the textile fibers.

Heavy metals concentrations in all examined textile fibers after wet digestion were found to be high, whereas in the artificial sweat extract they were low. However, the determination of the amounts passing into the body of heavy metals from textile products as a result of sweating is very important. To determine them, synthetic artificial sweat is commonly used as extraction media. The low solubility of heavy metals in the artificial sweat extract indicates the quality of the textile products.

The literature values of heavy metals in various textile products were given in Table 5. The nearest studies to our study in the literature were displayed by Doğan et al. [11] and Saracoglu et al. [5]. They reported that mean heavy metal concentrations were detected in cotton, polyester, nylon, and viscose cloth samples. Generally, heavy metal concentrations in our study were found to be similar to theirs. Tuzen et al. [4] found the concentrations of heavy metals to be in the range of $0.76-341 \mu \mathrm{g} \mathrm{g}^{-1}$ for $\mathrm{Cu}, 0.10-0.25 \mu \mathrm{g} \mathrm{g}^{-1}$ for $\mathrm{Cd}, 0.63-4.84 \mu \mathrm{g}$ $\mathrm{g}^{-1}$ for $\mathrm{Zn}, 1.02-2.50 \mu \mathrm{g} \mathrm{g}^{-1}$ for $\mathrm{Mn}, 3.55-34.3 \mu \mathrm{gg}^{-1}$ for $\mathrm{Fe}$, and $1.20-4.69 \mu \mathrm{g} \mathrm{g}^{-1}$ for $\mathrm{Ni}$ in cotton fabrics. These values are notably high in comparison to our study. In a study by Rezić and Steffan, minimum and maximum values of heavy metal concentrations were found $0.11-1.58 \mu \mathrm{g} \mathrm{mL}^{-1}$ for $\mathrm{Al}, 0.05-$ $1.95 \mu \mathrm{g} \mathrm{mL}^{-1}$ for $\mathrm{Cu}, 0.01-2.17 \mu \mathrm{g} \mathrm{mL}^{-1}$ for $\mathrm{Mn}$, and $0.05-$ $0.10 \mu \mathrm{g} \mathrm{mL}^{-1}$ for $\mathrm{Ni}$ [6]. Heavy metal contents in our study were found to be higher than those in their study.

The heavy metal contents of the examined various textile fibers were found to vary significantly from one color to another color and from a type to another. The results obtained from this study show that heavy metal concentrations in textile fibers were not thought to create a risk factor for human health. However, the concentrations of lead were found a little higher than the Oeko-Tex standards in cotton, acrylic, polyester, and polypropylene fibers. People are exposed to heavy metals coming from textile materials due to daily contact with textiles like clothes, bed linen, and similar products. Some of these metals may trigger allergic reactions and much worse. Therefore, textile fibers should be analyzed more often. MP-AES technique is well suited for rapid and sensitive monitoring of heavy metals in textile fibers.

\section{Conflict of Interests}

The authors declare that there is no conflict of interests regarding the publication of this paper.

\section{References}

[1] http://www.oecotextiles.com/PDF/textile_industry_hazards .pdf.
[2] D. Katovic, I. Piljac, and I. Soljacic, "Determination of iron and copper in textile materials by anodic stripping voltametry," Textile Research Journal, vol. 55, no. 1, pp. 20-23, 1985.

[3] Z. Grabaric, L. Bokic, and B. Stefanovic, "Determination of iron in raw materials, during fabric processing, and in wastewaters of the textile industry," Journal of AOAC International, vol. 82, no. 3, pp. 683-688, 1999.

[4] M. Tuzen, A. Onal, and M. Soylak, "Determination of trace heavy metals in some textile products produced in Turkey," Bulletin of the Chemical Society of Ethiopia, vol. 22, no. 3, pp. 379-384, 2008.

[5] S. Saracoglu, U. Divrikli, M. Soylak, L. Elci, and M. Dogan, "Determination of trace elements of some textiles by atomic absorption spectrometry," Journal of Trace and Microprobe Techniques, vol. 21, no. 2, pp. 389-396, 2003.

[6] I. Rezić and I. Steffan, "ICP-OES determination of metals present in textile materials," Microchemical Journal, vol. 85, no. 1, pp. 46-51, 2007.

[7] I. Rezić, M. Zeiner, and I. Steffan, "Determination of 28 selected elements in textiles by axially viewed inductively coupled plasma optical emission spectrometry," Talanta, vol. 83, no. 3, pp. 865-871, 2011.

[8] I. Aydin, "Comparison of dry, wet and microwave digestion procedures for the determination of chemical elements in wool samples in Turkey using ICP-OES technique," Microchemical Journal, vol. 90, no. 1, pp. 82-87, 2008.

[9] E. A. Menezes, R. Carapelli, S. R. Bianchi et al., "Evaluation of the mineral profile of textile materials using inductively coupled plasma optical emission spectrometry and chemometrics," Journal of Hazardous Materials, vol. 182, no. 1-3, pp. 325-330, 2010.

[10] B. Pranaityte, A. Padarauskas, and E. Naujalis, "Determination of metals in textiles by ICP-MS following extraction with synthetic gastric juice," Chemija, vol. 19, no. 3-4, pp. 43-47, 2008.

[11] M. Doğan, M. Soylak, L. Elçi, and A. Von Bohlen, "Application of total reflection X-ray fluorescence spectrometry in the textile industry," Mikrochimica Acta, vol. 138, no. 1-2, pp. 77-82, 2002. 

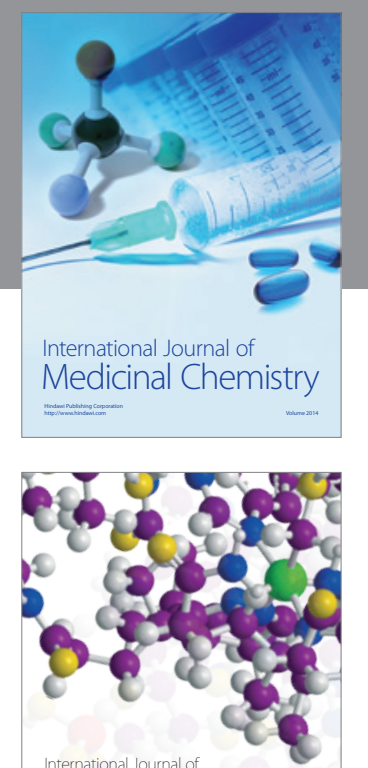

\section{Carbohydrate} Chemistry

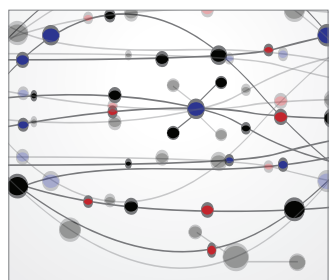

The Scientific World Journal
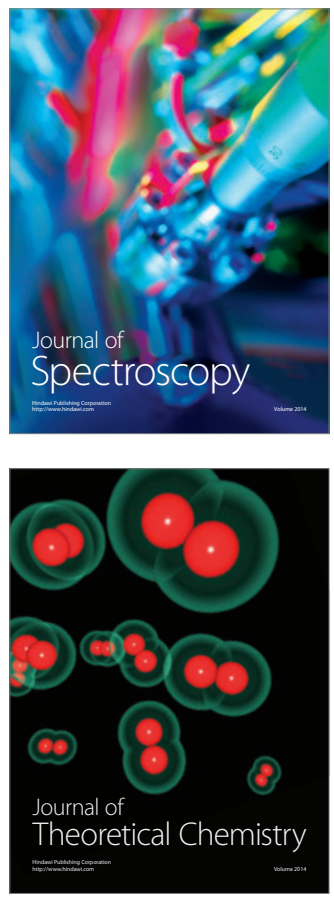
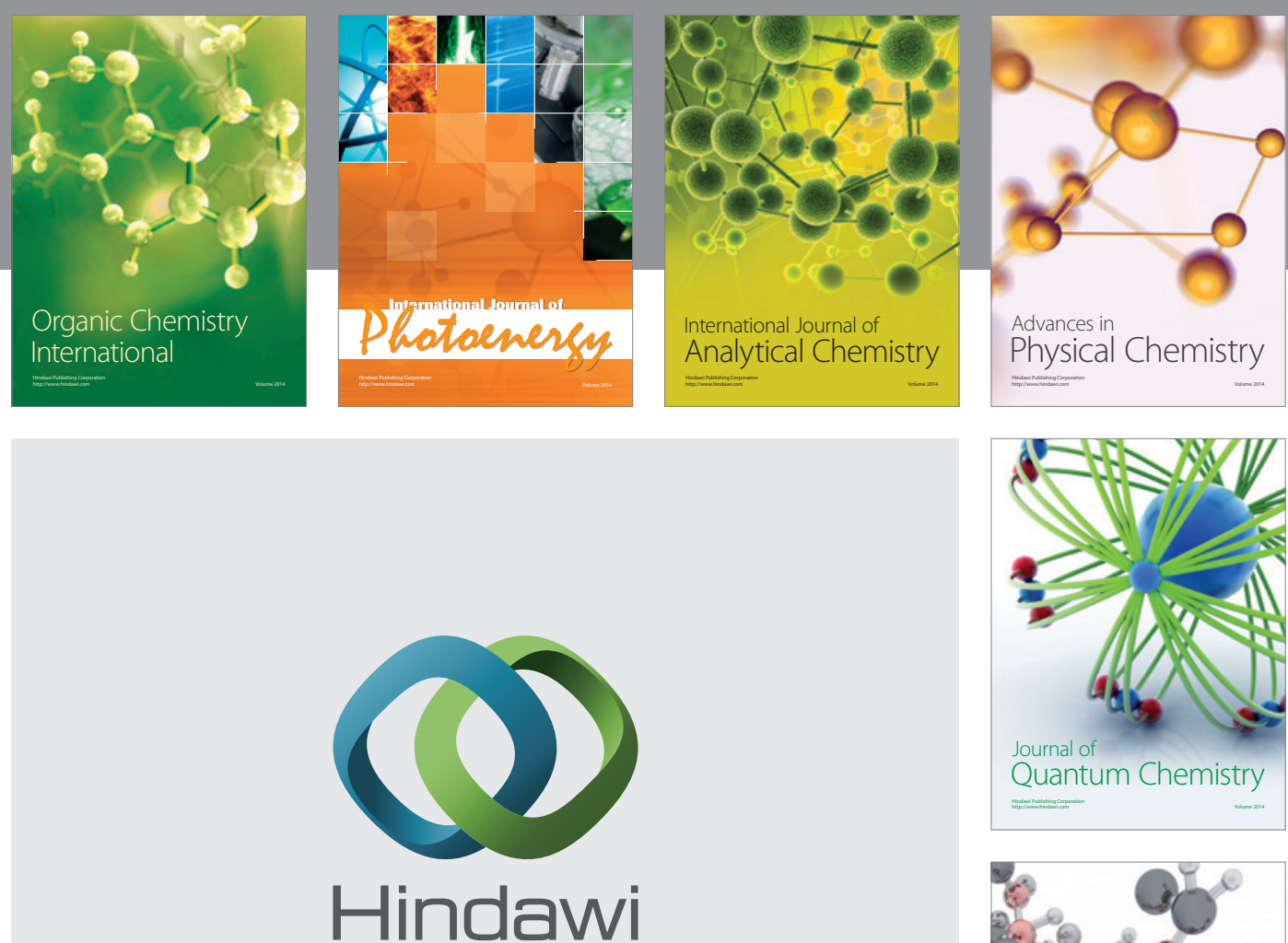

Submit your manuscripts at

http://www.hindawi.com

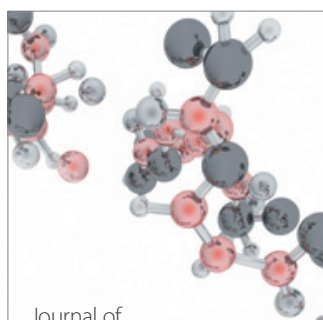

Analytical Methods

in Chemistry

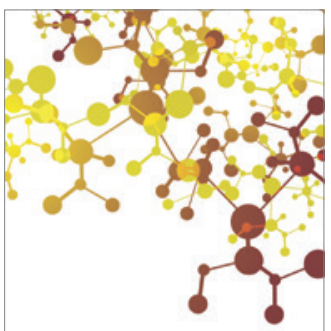

Journal of

Applied Chemistry

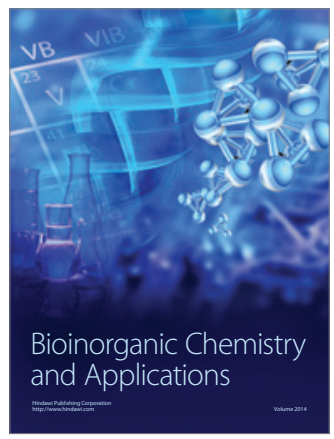

Inorganic Chemistry
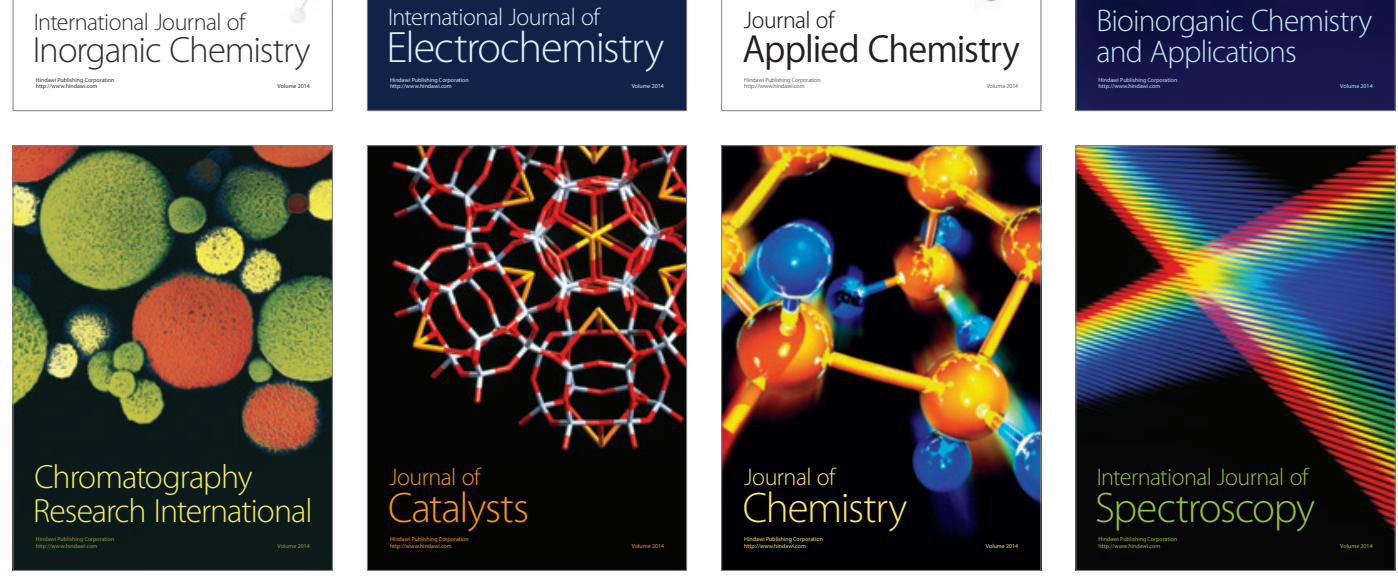